\title{
Corrigendum \\ Corrigendum to "Fault Location of Active Distribution Networks Based on the Golden Section Method"
}

\author{
Haizhu Yang, ${ }^{1}$ Xiangyang Liu $\left(\mathbb{D},{ }^{1}\right.$ Yiming Guo, ${ }^{1}$ and Peng Zhang $^{2}$ \\ ${ }^{1}$ School of Electrical Engineering and Automation, Henan Polytechnic University, 454000 Jiaozuo, China \\ ${ }^{2}$ School of Electrical Engineering and Automation, Tianjin University, 300072 Tianjin, China \\ Correspondence should be addressed to Xiangyang Liu; 211707010014@home.hpu.edu.cn
}

Received 5 February 2021; Accepted 5 February 2021; Published 23 March 2021

Copyright (C) 2021 Haizhu Yang et al. This is an open access article distributed under the Creative Commons Attribution License, which permits unrestricted use, distribution, and reproduction in any medium, provided the original work is properly cited.

The article titled "Fault Location of Active Distribution Networks Based on the Golden Section Method" [1] was found to contain material from a previously published article [2]. Therefore, the article has been revised as follows:

Aiming at the problem of fault location in active distribution network with distributed energy resources (DERs), a fault location method based on the concepts of minimum fault reactance and golden section is proposed in this paper. Considering the influence of distributed energy resources supply on fault point current in distribution network, an improved trapezoidal iteration method is proposed for load flow analysis and fault current calculation. 'is method only needs to measure the synchronous current of the distributed energy resource and does not need to measure the voltage information. 'erefore, the investment in equipment is reduced. Validation is made using the IEEE 34-node test feeder. Simulation results show that the method is suitable for fault location of distribution network with multiple distributed generators. 'is method can accurately locate the faults of the active distribution network under different conditions.

\section{Introduction}

With the development of society, more and more DERs are connected to the distribution network, which leads to more clean energy applications and brings huge economic benefits [1-3]. The integration of distributed generation (DG) and its synchronous operation with power grid is one of the challenges we now face [4-6]. In this case, the supervision and management of power grid with self-healing function become more complex. Fast fault location is an important task to restore power supply when the distribution network fails. Although technology is developing rapidly, due to the increasing expectations of users, the fault location technology of distribution network still needs improvement.

At present, the fault location methods for active distribution network are based on traveling wave method, artificial intelligence method, and impedance method. Traveling wave analysis is widely used. In [7-10], the traveling wave fault location method was introduced, but this method requires a higher sampling frequency and has many links, which has some impacts on the overall reliability. In [11], the evaluation function for the characteristics of active distribution network was redefined, and a suitable immune algorithm was proposed. In [12], a radial basis function neural network model was proposed based on the fault information uploaded by the distribution network monitoring and data acquisition system. The improved algorithm is applied to fault location of active distribution network. In [13], a fault location method based on wavelet fuzzy neural network for postfault transient and steady-state measurements is proposed. Although the abovementioned artificial intelligence-based fault location method has high performance, it requires a lot of data to learn, and its accuracy is affected by the database. In [14-17], fault location is achieved by collecting synchronous current and voltage vectors. This method needs to measure synchronous current and voltage information, thus increasing equipment investment. Impedance-based fault location method is one of the current research methods and has achieved good results in applications [18-21]. However, this method cannot solve the problem of fault location in the active distribution network. In $[22,23]$, the effect of DG on the distribution network was simulated using a synchronous machine, but 
only one DER was considered, and the effect of different DER penetration levels was not analyzed [24].

The fault location method proposed in this paper combines the golden section method and the trapezoidal iteration technique to analyze the fault location of the active distribution network under different operating conditions [25]. This method eliminates the potential relationship between the accuracy of fault location and search step size. In addition, this method only needs to collect the synchronous current vector of the DER, which reduces the equipment investment. It improves the accuracy of fault location and reduces costs.

\section{Minimum Fault Reactance}

The method proposed in this paper is to use the minimum fault reactance method [26]. Assuming that the fault points of the analysis line segment are random, the fault reactance equation can be obtained by calculating the fault reactance through the analysis circuit [27]. Calculate the fault reactance at each assumed fault point. Repeat this process on all line segments. Most line faults have impedance characteristics, so the fault location can be solved by solving the minimum fault reactance value. In the distribution network shown in Figure 1, there is a line fault point between node $n$ and $n+1$. Because the fault line segment is unknown in advance, therefore, the first line section of the substation is considered first.

As shown in Figure 2, by controlling the closing and opening of switches $S_{1}, S_{2}, S_{3}$, and $S_{4}$, the active distribution network can obtain different fault types. A generalized expression of the fault point voltage $V_{f}$ is obtained by analyzing Figure 2 [28].

$$
\left[V_{f}\right]=\left([U]+\frac{1}{2} x^{2}\left[Z_{a b c}\right] \cdot\left[Y_{a b c}\right]\right) \cdot\left[V_{n}^{f}\right]-x\left[Z_{a b c}\right] \cdot\left[I_{n}^{f}\right],
$$

where $\left[Z_{a b c}\right]$ is the impedance matrix between nodes $n$ and $n+1,\left[Y_{a b c}\right]$ is the admittance matrix, $[U]$ is the third-order identity matrix, $\left[V_{n}^{f}\right]$ is the fault voltage vector of node $n$, $\left[I_{n}^{f}\right]$ is the fault current vector, $x$ is the normalized fault distance which is the ratio of the fault distance of the line to its length.

Considering the influence of the downstream current, use formula (2) to calculate the fault current:

$$
\left[I_{f}\right]=\left[I_{u}\right]+\left[I_{d}\right]
$$

where $\left[I_{u}\right]$ is the upstream fault current vector, $\left[I_{d}\right]$ is the downstream fault current vector, $\left[I_{u}\right]$ is calculated by formula (3), and $\left[I_{d}\right]$ is calculated by using improved trapezoidal iteration load flow calculation method.

$$
\begin{aligned}
{\left[I_{u}\right]=} & -\left(x\left[Y_{a b c}\right]+\frac{1}{4} x^{3}\left[Y_{a b c}\right] \cdot\left[Z_{a b c}\right] \cdot\left[Y_{a b c}\right]\right)\left[V_{n}^{f}\right] \\
& +\left([U]+\frac{1}{2} x^{2}\left[Z_{a b c}\right] \cdot\left[Y_{a b c}\right] \cdot\left[I_{n}^{f}\right]\right) .
\end{aligned}
$$

Generalized expression of fault reactance obtained by formulas (1) and (2):

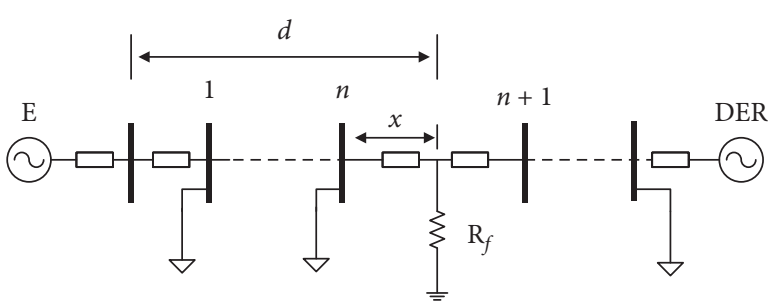

FIgURe 1: Single-line diagram of distribution network.

$$
X_{f}=\operatorname{Im}\left\{\frac{S-q_{m} \cdot V_{f m}-S-q_{n} \cdot V_{f n}}{S-q_{m} \cdot I_{f m}}\right\},
$$

where $V_{f m}$ is the voltage vector of fault phase $m$ and $V_{f n}$ is the voltage vector of fault phase $n$. When $S-q_{m}, S-q_{n}$ is 1 , it indicates that the phase has a fault; otherwise, it is $0 . \operatorname{Im}$ is the imaginary part solve operation. Table 1 shows the measured voltage and current vectors for solving the reactance of different fault types.

\section{Golden Section Method}

The primary task of the fault location method based on the minimum fault reactance value is to find the minimum reactance. The previous methods usually use a constant step length of $\Delta m$ or a second derivative to solve the problem [29]. The golden section method proposed in this paper selects the test point by the principle of symmetry and keeping the reduction ratio [30]. By comparing the function values of the test points, the search interval is shortened to reach the minimum interval of the minimum point. The accuracy and speed of the search method are related to the step length. The golden section method takes fewer test points to determine the minimum fault reactance value, which improves the accuracy and speed of calculation.

The golden section method uses the golden section rule to select two symmetrical points in the search interval and then compares the function values at two points to determine a new search interval. In the fault location problem $t \in[a, b]$, it indicates the change of the line fault distance. Select two golden points $t_{1}$ and $t_{2}$ in the interval $[a, b]$ and then use the golden section method to search the interval. The first search point $t_{1}$ takes 0.618 of $[a, b]$, and the second search point $t_{2}$ takes the symmetric point of $t_{1}$, that is, 0.382 of $[a, b]$, as shown in Figure 3 .

Calculate the values of $X_{f\left(t_{1}\right)}, X_{f\left(t_{2}\right)}$ and compare the sizes of the two values. If $X_{f\left(t_{1}\right)}<X_{f\left(t_{2}\right)}$, it indicates that $t_{1}$ is an effective point, so the interval $\left[a, t_{2}\right]$ is removed, the interval $\left[t_{2}, b\right]$ is reserved, and the new interval $\left[a_{1}, b_{1}\right]=\left[t_{2}, b\right]$ :

$$
\begin{aligned}
& t_{1}=a+0.618(b-a), \\
& t_{2}=a+0.382(b-a) .
\end{aligned}
$$

Conversely, if $X_{f\left(t_{1}\right)}>X_{f\left(t_{2}\right)}$, then $t_{2}$ is the effective point, the interval $\left[t_{1}, b\right]$ is removed, the interval $\left[a, t_{1}\right]$ is reserved, and the new interval $\left[a_{1}, b_{1}\right]=\left[a, t_{1}\right]$. Judged whether the new interval is smaller than the allowable error $\varepsilon$. If the allowable error is not reached, the above search process is continued in the new interval until the search interval $\left[a_{i}, b_{i}\right]$ is smaller than the allowable error $\varepsilon$ : 


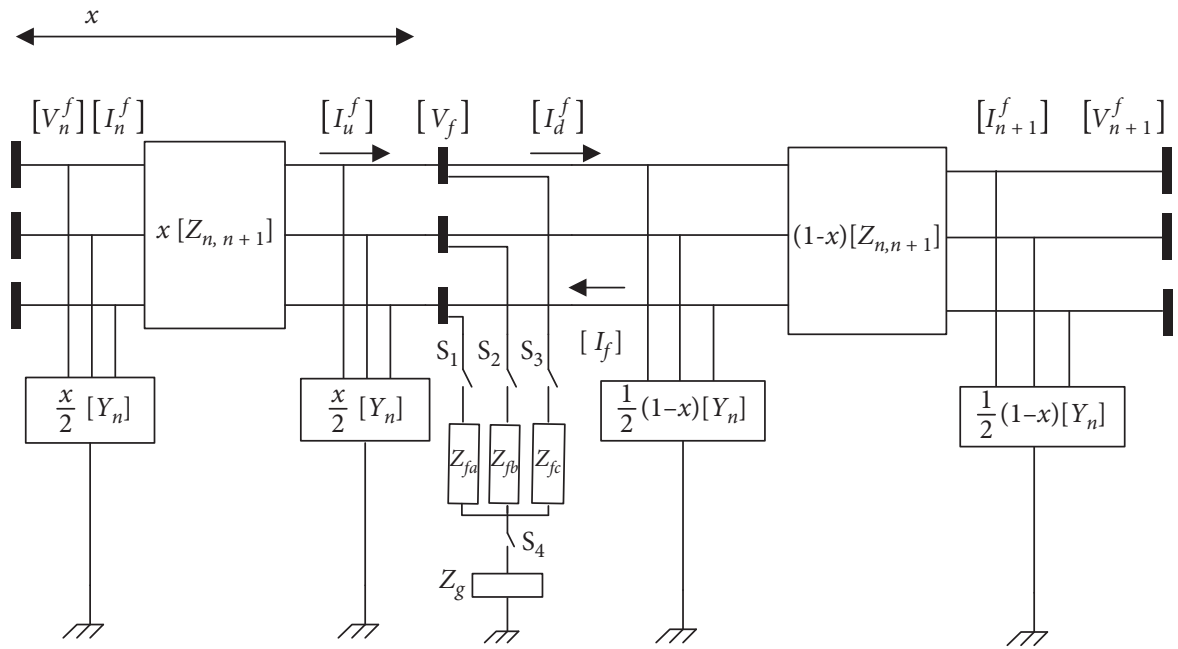

FIGURE 2: Distribution network fault model.

TABLE 1: Solving fault reactance requirements.

\begin{tabular}{|c|c|c|c|c|c|c|c|c|}
\hline \multirow[t]{2}{*}{ Fault type } & \multirow{2}{*}{$\frac{S-q_{m}}{1}$} & \multirow{2}{*}{$\frac{\text { S-qn }}{0}$} & \multicolumn{2}{|c|}{$\begin{array}{c}m \text { phase }\left(S-q_{m}\right. \\
\left.V_{f m}\right)\end{array}$} & \multicolumn{2}{|c|}{$n$ phase $\left(S-q_{n} V_{f n}\right)$} & \multicolumn{2}{|c|}{$\begin{array}{l}m \text { phase fault } \\
\text { current }\end{array}$} \\
\hline & & & $a$ & $V_{f a}$ & $b, c$ & 0 & $a$ & $I_{f a}$ \\
\hline \multirow[t]{3}{*}{ Single-phase faults } & 1 & 0 & $b$ & $V_{f b}$ & $a, c$ & 0 & $b$ & $I_{f b}$ \\
\hline & 1 & 0 & $c$ & $V_{f c}$ & $a, b$ & 0 & $c$ & $I_{f c}$ \\
\hline & 1 & 1 & $a$ & $V_{f a}$ & $b, b-c$ & $V_{f b}$ & $a$ & $I_{f a}$ \\
\hline \multirow[t]{2}{*}{ Multiphase faults } & 1 & 1 & $b$ & $V_{f b}$ & $c, a-c$ & $V_{f c}$ & $b$ & $I_{f b}$ \\
\hline & 1 & 1 & $c$ & $V_{f_{c}}$ & $a, a-b$ & $V_{f a}$ & $c$ & $I_{f c}$ \\
\hline
\end{tabular}

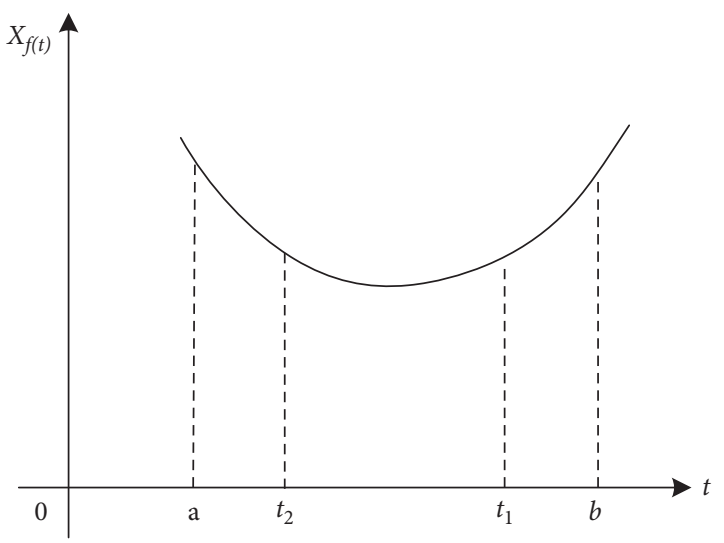

FIGURE 3: Golden section method.

$$
\left|b_{i}-a_{i}\right|<\varepsilon
$$

The search is stopped when the allowable error is reached, and finally the fault distance is determined according to the interval:

$$
x=\frac{b_{i}+a_{i}}{2} .
$$

\section{Active Distribution Network Fault Location}

4.1. Establishing the Minimum Fault Reactance Model. The golden section method is used to model and analyze the fault location problem, and the fault location is transformed into the optimal solution problem. The optimization formula is as follows:

$$
\left\{f=\min \left|X_{f}(x)\right|, \quad x \in[0,1] .\right.
$$

The objective function is given by the absolute value of formula (4), $x$ is the normalized fault distance, and this function is used to solve the fault location. Since the faulted line is unknown, it is necessary to apply this method in each line of the distribution network.

4.2. Analysis Process. The flow diagram of the analysis method proposed in the paper is shown in Figure 4, which consists of four steps. The data processing for each step is as follows:

\section{Step 1. Upload data:}

Upload data of the active distribution network system, such as distribution system topology, load, and line electrical parameters. In addition, there are the voltage and current vectors of the substation at fault time obtained by the Fourier transform and the synchronous current vector of the DER.

\section{Step 2. Fault location:}

Calculate the fault current according to formula (2), and then calculate the fault reactance using formula (4). Assume that $\left[I_{d}\right]=-\left[I_{n}^{p}\right]$, where $\left[I_{n}^{p}\right]$ is the prefault current of node $n$. Formula (7) is used to calculate the fault distance of the line. The fault current is defined as 


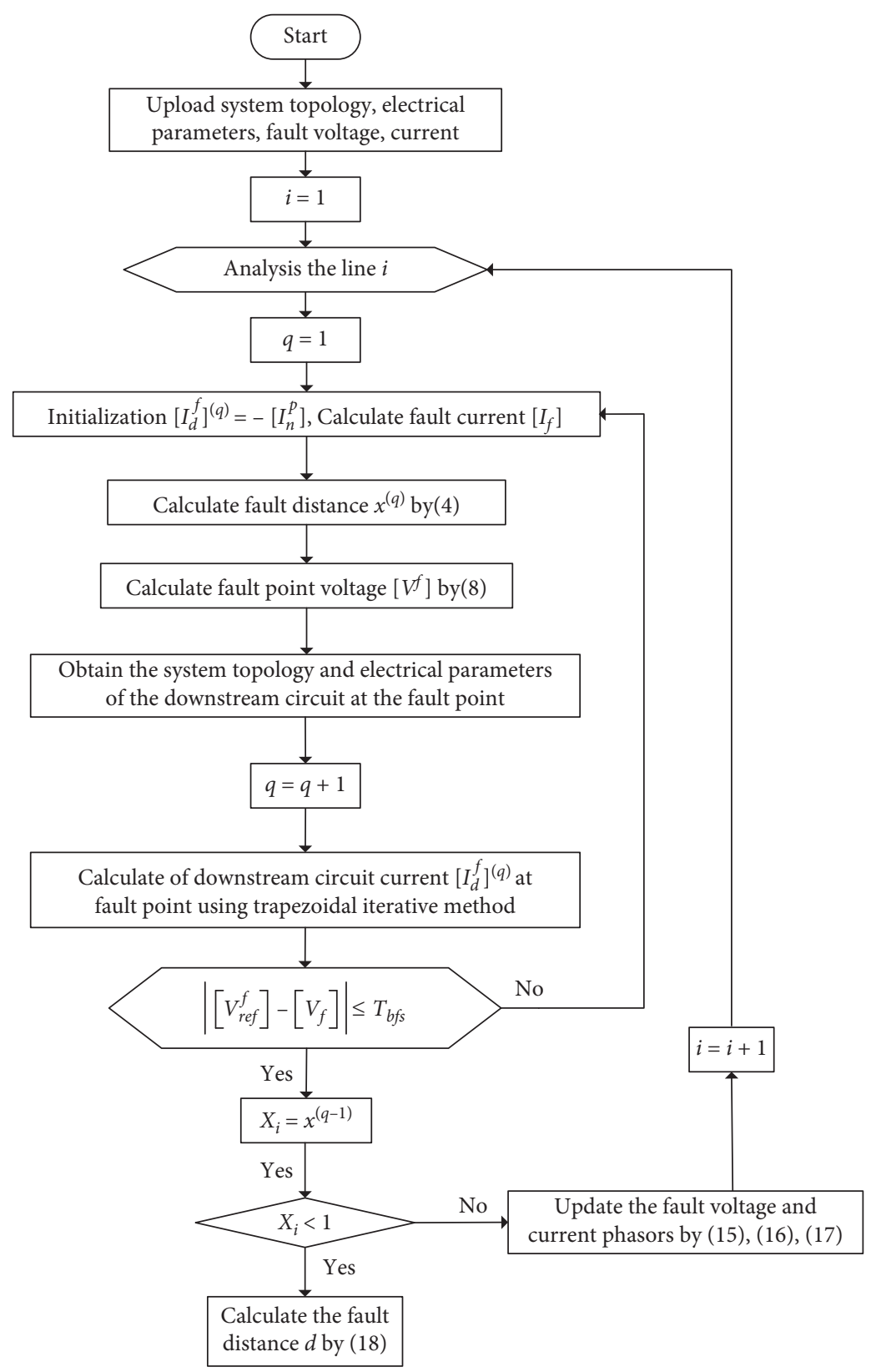

FIgURE 4: Flowchart of algorithm.

a function of $m$, and then an iterative calculation is performed to update the downstream fault current $\left[I_{d}\right]$. Step 3. Calculation of downstream fault current:

Because the feeder of the active distribution network is radial, the traditional iterative method for power flow analysis has poor convergence in the active distribution network. Therefore, the improved trapezoidal iteration method is used to calculate the fault current of the radial power distribution system. As shown in Figure 5, this figure illustrates the fault distance in the circuit which is $m$ and then analyzes the downstream circuit of the fault point. Assume that the system load is constant impedance during the fault and DER is the current source. The current is measured by the installed synchronous current device, and the downstream fault

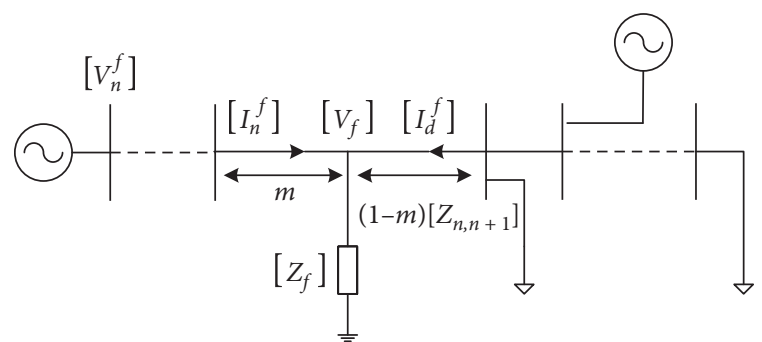

FIgURe 5: Downstream circuit of fault point.

current value is obtained by an improved trapezoidal iteration method. This method has two processes: forward and backward [31]. 
In the forward process, calculate the voltage vector [32] from the source node to the downstream node, as shown in the following formula:

$$
\left[V_{n+1}^{f}\right]=[A] \cdot\left[V_{n}^{f}\right]-[B] \cdot\left[I_{n+1}^{f}\right] .
$$

In the backward process, the current vector is calculated from the load node to the source node by using the voltage and circuit model calculated and derived from the most recent forward calculation, as shown in the following formula:

$$
\left[I_{n}^{f}\right]=[c] \cdot\left[V_{n+1}^{f}\right]+[d] \cdot\left[I_{n+1}^{f}\right] .
$$

The voltage and current vectors in formulas (9) and (10) are the values of nodes $n$ and $n+1$ at fault. $[A],[B],[c]$, and $[d]$ are impedance matrices that vary from each system component type. Finally, a new source voltage is calculated based on the current.

When the algorithm is executed, in the first forward process, the voltages of all nodes of the system are initialized to the voltages of the fault points. In the backward process, the terminal current $\left[I_{n+1}^{f}\right]$ and the new source voltage are calculated using the voltage and circuit model obtained from the most recent forward calculation. System nodes can connect different components. When connected to parallel components, such as loads or capacitors, current $\left[I_{n+1}^{f}\right]$ is calculated by the admittance matrix:

$$
\left[I_{n+1}^{f}\right]=\left[Y_{n+1}^{f}\right] \cdot\left[V_{n+1}^{f}\right],
$$

where $\left[Y_{n+1}^{f}\right]$ is the admittance matrix of the parallel components. When DER is connected, current $\left[I_{n+1}^{f}\right]$ is provided by the corresponding synchronous current measuring device:

$$
\left[I_{n+1}^{f}\right]=-\left[I_{\mathrm{IED}_{n+1}}^{f}\right] .
$$

Iterative search until the voltage error at the reference node is less than the specified $T_{b f s}$ :

$$
|| V_{\text {ref }}^{f}|-| V_{f}|| \leq T_{b f s} .
$$

Finally, when convergence is reached, the current at the reference node is taken as the fault current of the downstream circuit.

Step 4. Update the voltage and current vector of the downstream circuit:

The steps 2 and 3 are used to analyze and calculate the line sections of the system. At this time, the calculation accuracy is improved by calculating the voltage and current of the downstream circuit nodes:

$$
\begin{aligned}
& {\left[\begin{array}{c}
V_{n+1}^{f} \\
I_{n+1}^{\prime}
\end{array}\right]=\left[\begin{array}{cc}
d_{l} & -b_{l} \\
-c_{l} & a_{l}
\end{array}\right] \cdot\left[\begin{array}{c}
V_{n}^{f} \\
I_{n}^{f}
\end{array}\right],} \\
& {\left[I_{n+1}^{f}\right]=\left[I_{n+1}{ }^{\prime}\right]-\left[I_{L_{n+1}}^{f}\right],}
\end{aligned}
$$

where $\left[I_{n+1}^{\prime}\right]$ is the line current of node $n+1$ without considering other branches, $\left[I_{n+1}\right]$ is the current at node $n+1$ when considering other branches, and $\left[I_{L_{n+1}}\right]$ is the sum of the currents of the connection branches at node $n+1$. For the node containing the DER branch, current $\left[I_{n+1}\right]$ is

$$
\left[I_{n+1}^{f}\right]=\left[I_{n+1}^{\prime}\right]-\left[I_{L_{n+1}}^{f}\right]+\left[I_{\mathrm{DER}}^{f}\right] .
$$

where $\left[I_{\mathrm{DER}}\right]$ is the current flowing from DER to node $n+1$; this current is calculated by the step 3 . If the fault is within the analyzed line section, the expression for the fault distance is

$$
d=\sum_{i=1}^{n-1} L_{i}+X_{i} \cdot L_{n}
$$

where $L_{i}$ is the length of the analyzed line $i$ and $X_{i}$ is the normalized fault length of the last line $L_{n}$, the value of which is calculated by formula (7).

\section{Simulation Analysis}

5.1. Simulation Modeling. Using PSCAD to build an IEEE 34-node test feeder system with different types of wires and loads, the working voltage level is $30 \mathrm{kV}$ and the total length of the line is $58 \mathrm{~km}$. It is changed by adding three DER with a penetration level of $10 \%$ in the system; the changed IEEE 34 -node test feeder system is shown in Figure 6. The system is simulated and analyzed. Table 2 presents a summary of the tests realized. When the system fails, its fault data are obtained and the fault distance is calculated by the golden section method.

5.2. Analysis of Results. The accuracy of the method is verified by analyzing the following scenarios. Considering the error between the calculated result and the actual value, the simulation result is evaluated by the following formula:

$$
\% \text { Error }=\left|\frac{d-d_{\text {rel }}}{d_{\text {tol }}}\right| \cdot \% \text {, }
$$

where $d$ is the calculated fault distance, $d_{\text {rel }}$ is the actual fault distance, and $d_{\text {tol }}$ is the total length of the line.

5.2.1. Effect of Fault Resistance. When analyzing the effect of fault resistance on the method, different fault types are considered, as shown in Figure 7. The results show that under the influence of fault resistance, the maximum error of fault location is $0.16 \%$, and this error occurs during single-phase ground fault. In the $58 \mathrm{~km}$ test feeder, the average fault distance calculate error of this method is about $25 \mathrm{~m}$. This shows that the method has high accuracy of fault location.

In the figure, $L-g$ is a single-phase ground fault, $L L$ is a two-phase short-circuit fault, $L L-g$ is a two-phase ground fault, $L L L$ is a three-phase short-circuit fault, and $L L L-g$ is a three-phase ground fault. 


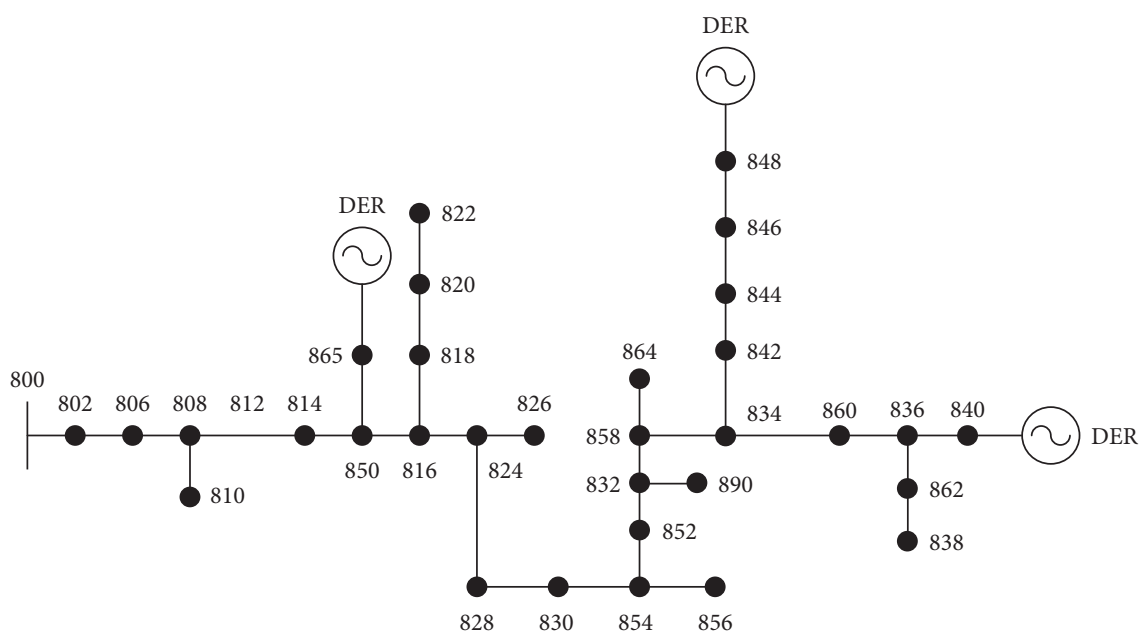

FIGURE 6: IEEE 34-node system.

TABle 2: Studied cases to validate the proposed method.

\begin{tabular}{lccc}
\hline Test & Fault condition & Fault description & Fault number \\
\hline Fault resistance & All types & Fault resistance between $0 \Omega$ and $100 \Omega$ & 2314 \\
Fault distance & Single-phase phase-to-phase & Fault resistance: $0 \Omega$ and $100 \Omega$ & 387 \\
Load variation & Single-phase & Load variation: $40-70 \%, 70-100 \%, 100-130 \%$ & 129 \\
DER penetration level & Single-phase & DER penetration level: 10\%, 20\%, 30\% & 129 \\
Total tests & & & 2959 \\
\hline
\end{tabular}

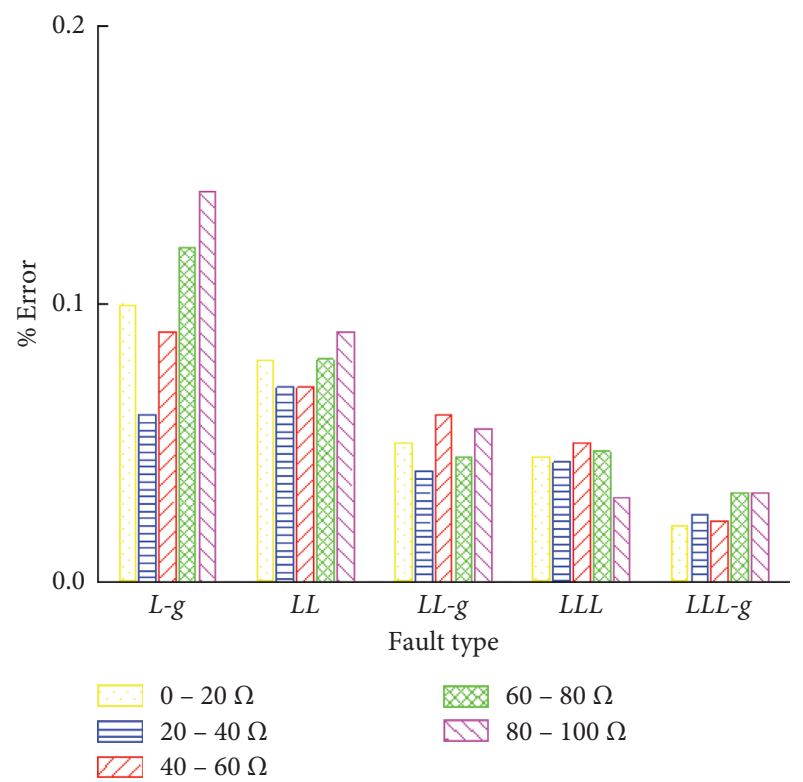

FIgURE 7: The influence of fault types on fault location.

5.2.2. Effect of Fault Distance. The results of Figures 8 and 9 show the effect of fault distance on the proposed method.

It can be concluded from the analysis that the error increases slightly with increasing fault distance, as shown in Figures 8 and 9, and as the fault reactance value increases, this effect will be amplified, but still less than $0.14 \%$. In the $58 \mathrm{~km}$ test feeder, the error is less than $80 \mathrm{~m}$. Therefore, it is observed from the above that the behavior of the method is little affected by the fault distance.

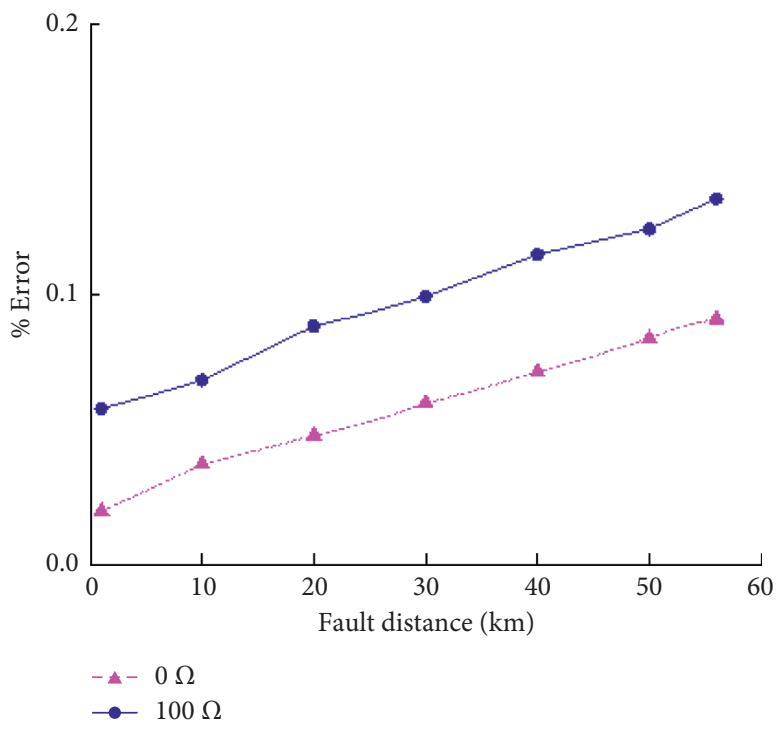

Figure 8: Performance curve for the proposed method, considering the fault distance effect for faults A-g.

5.2.3. Effect of Load Variation. Since the load in the active distribution network system varies greatly, this will have some effects on the system. Therefore, it is necessary to analyze the effect of load variations on this method. As shown in Figure 10, the results show that the accuracy of the method is related to the value of the load. Because the load variation compensation method is not used in the simulation, the fault distance calculated by this method is smaller than the actual fault distance when the load level is low. This 


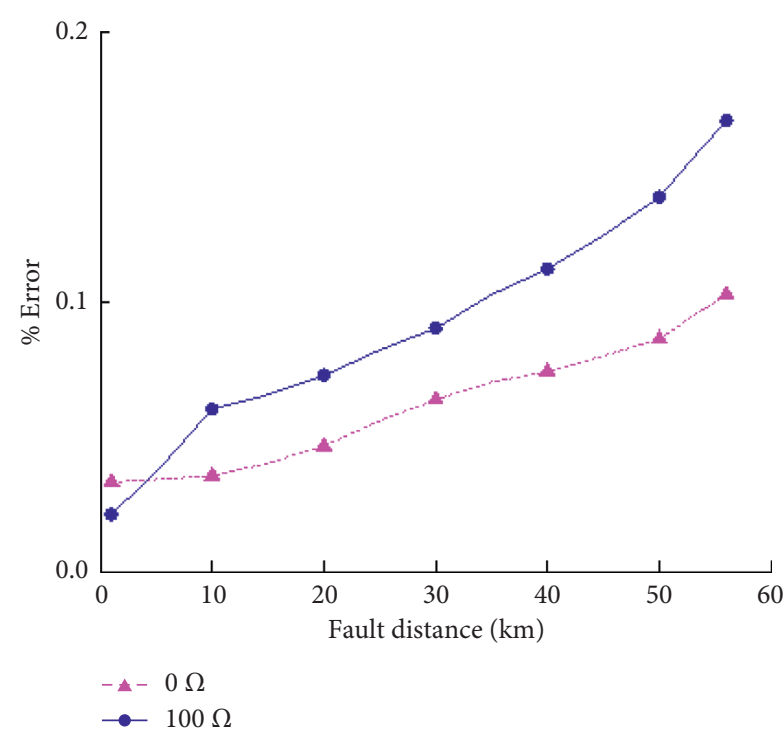

Figure 9: Performance curve for the proposed method, considering the fault distance effect for faults BC.

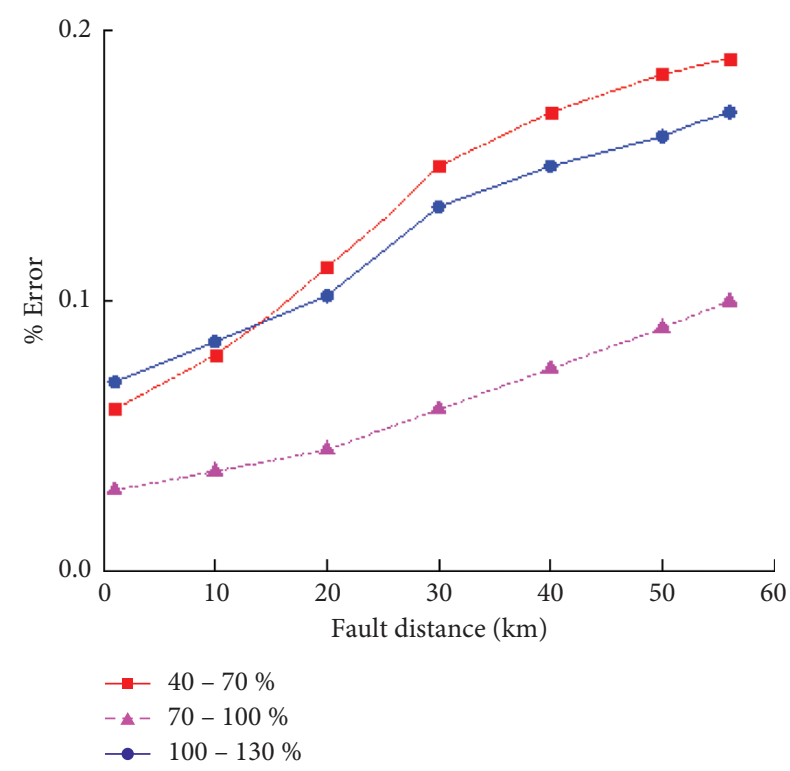

FIgURE 10: The influence of load variation on fault location.

phenomenon occurs because the load conditions used by the proposed method are higher than the actual load conditions of the system, so the impedance observed by the proposed method from the substation is smaller. In contrast, for high load levels, the method calculates a fault distance that is higher than the actual fault distance. In this scenario, the error caused by the load variation is less than $0.18 \%$. In the $58 \mathrm{~km}$ test feeder, the error is less than $104 \mathrm{~m}$. This method still has good performance.

5.2.4. Effect of DER Penetration Level. Add three DERs with $10 \%$ penetration to the IEEE 34-node test feeder model. Analyze the effect of DER penetration level on fault location of active distribution networks. As shown in Figure 11, with

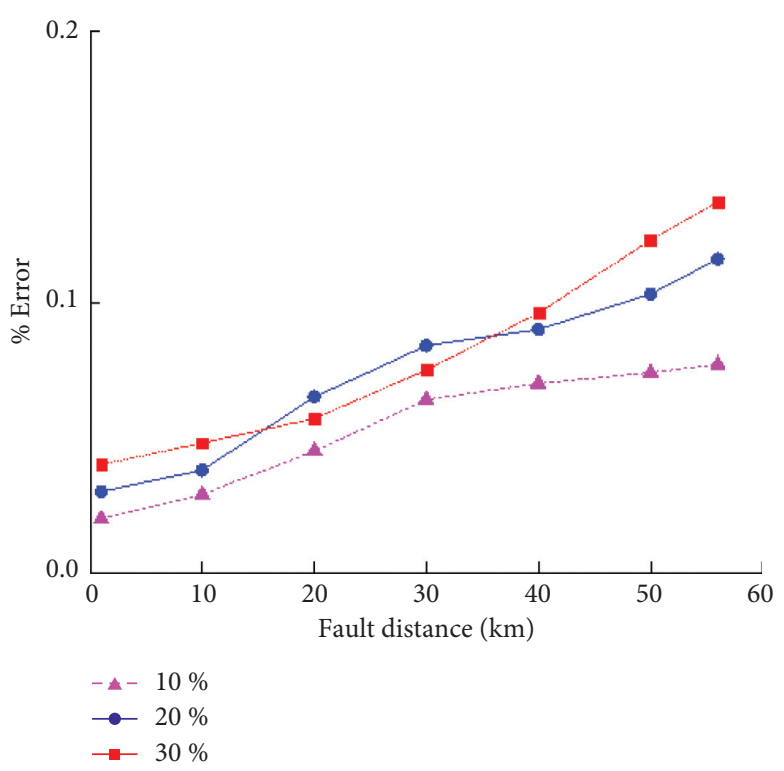

FIGURE 11: The influence of DER penetration level on fault location.

the increase of DER penetration level, the calculated fault distance will be greater than the actual fault distance. This phenomenon is due to the increase in DER penetration, which leads to an increase in the error in the calculation of the current from the DER to the fault point. In this paper, an improved trapezoidal iteration method is used to calculate the current value, which reduces the error in calculating the current value. Thus, the error value is less than $0.15 \%$ in this scenario. In the $58 \mathrm{~km}$ test feeder, the error is less than $87 \mathrm{~m}$. The method proposed in this paper still has high accuracy of fault location.

5.3. Comparison Test. The two methods that have been implemented are compared with the proposed analytical methods: Nunes's method [21] and Bedoya's method [27]. Nunes's method and Bedoya's method are formulated considering only one DER connected into network with a DER penetration level of $10 \%$. Thus, for the comparison of the proposed method with these methods, the two DERs were disconnected. These methods were validated and compared using scenario 1 , which evaluates the fault resistance effect. Test results are presented using the average error obtained for each fault type, as shown in Figure 12.

The test results show the better accuracy of our method when compared with the method proposed by Nunes and the method proposed by Bedoya. The average error of the method proposed by Nunes is $2 \%$ and the average error of the method proposed by Bedoya is $1.8 \%$. However, the average error of the method proposed by this paper is $0.6 \%$.

Finally, choose a test case to compare these two methods with the method proposed in this paper. Single-phase faults with resistance of $50 \Omega$. Figure 13 allows to understand why the Nunes's method presents a low performance: it depends on the fault resistance and the location of the fault. The figure also shows that the performance of the proposed method is better than Bedoya's method. The above is expected because 


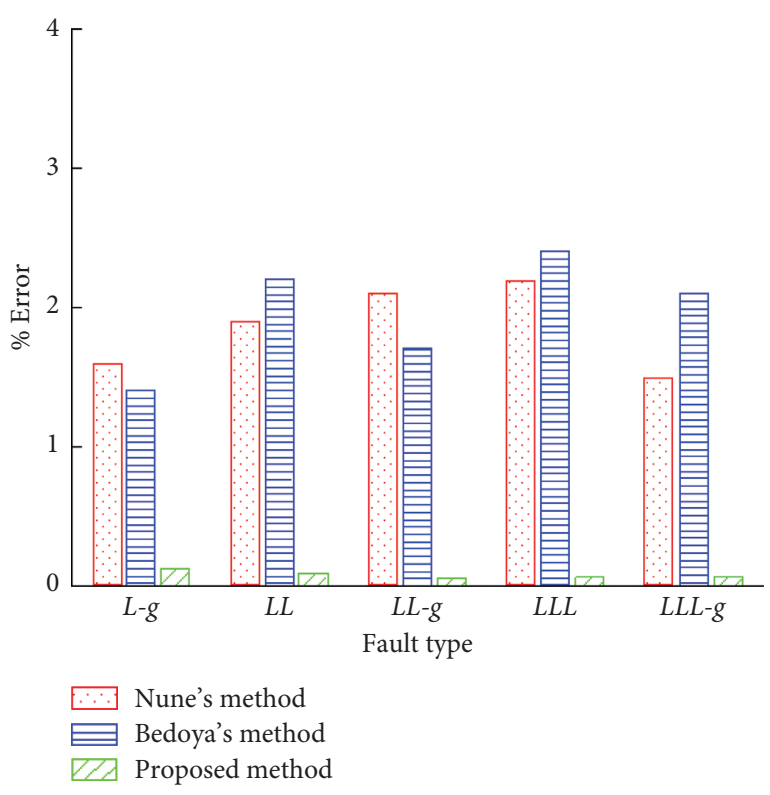

FIGURE 12: Error comparison of different methods in scenario 1.

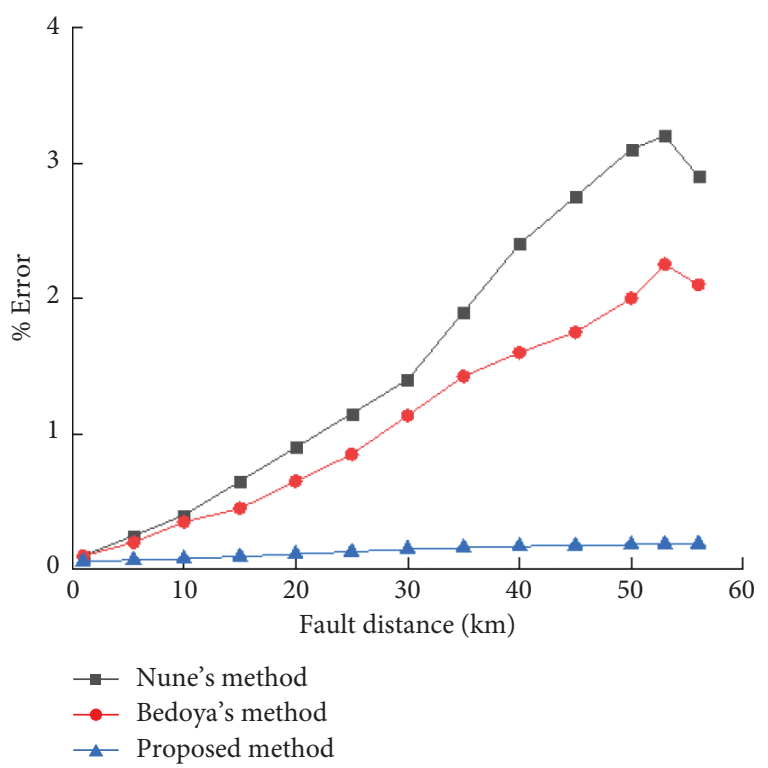

Figure 13: Performance curve for the proposed method and comparison with Nunes's method and Bedoya's method.

the method proposed by Bedoya is formulated using symmetrical components, and the unbalanced system is not considered in the formula derivation.

\section{Conclusions}

In this paper, a method for fault location of active distribution network is proposed. This method uses the golden section method to search for the minimum fault reactance value and converts the fault location problem into a search minimum problem. Compared with the traditional fixed step search method, the golden section method proposed in this paper improves the search speed. According to the different loads of the nodes, an improved trapezoidal iterative power flow calculation method is proposed in this paper. This method improves the accuracy of power flow calculation and fault location. The simulation results show that this method has a high efficiency and robustness under different fault conditions and operating conditions. This method only needs to measure the synchronous current vector of DER and does not need to measure the voltage vector. The fault location is realized by a simple method, which shows the potential of the method in practical application.

\section{Data Availability}

The data used to support the findings of this study are included within the article.

\section{Conflicts of Interest}

The authors declare that there are no conflicts of interest regarding the publication of this paper.

\section{Acknowledgments}

The study was supported by the National Natural Science Foundation of China (61703144).

\section{References}

(1) M. F. Akorede, H. Hizam, E. Pouresmaeil, "Distributed energy resources and benefits to the environment," Renewable and Sustainable Energy Reviews, vol. 14, no. 2, pp: 724-734, 2010.

(2) R. Cossent, L. Olmos, T. Gomez et al., "Distribution network costs under different penetration levels of distributed generation," European Transactions on Electrical Power, vol. 21, no. 6, pp: 1869-1888, 2011.

(3) B. Zhao, C. Wang, J. Zhou et al., "Present and Future Development Trend of Active Distribution Network," Automation of Electric Power Systems, vol. 38, no. 18, pp: 125-135, 2014.

(4) Y. Liu, N. N. Schulz, "Knowledge-based system for distribution system outage locating using comprehensive information," IEEE Transactions on Power Systems, vol. 17, no. 2, pp: 451-456, 2002.

(5) J. C. Gomez, J. Vaschetti, C. Coyos et al., "Distributed generation: Impact on protections and power quality," IEEE Latin America Transactions, vol. 11, no. 1, pp: 460-465, 2013.

(6) K. Sun, Q. Chen, Z. Gao, “An automatic faulted line section location method for electric power distribution systems based on multisource information," IEEE Transactions on Power Delivery, vol. 31, no. 4, pp: 1542-1551, 2016.

(7) L. De Andrade, T. P. De Leao, "Fault Location for Transmission Lines Using Wavelet," IEEE Latin America Transactions, vol. 12, no. 6, pp: 1043-1048, 2014. 
(8) S. G. Ferhatbegovic, A. Marusic, I. Pavic, "Single Phase Fault Distance Estimation in Medium Voltage Distribution Network Based on Traveling Waves," International Review of Electrical Engineering-IREE, vol. 7, no. 1, pp: 3532-3541, 2012.

(9) R. J. Hamidi, H. Livani, "A Recursive Method for Traveling-Wave Arrival-Time Detection in Power Systems," IEEE Transactions on Power Delivery, vol. 34, no. 2, pp: 710-719, 2019.

(10) S. Azizi, M. Sanaye-Pasand, M. Abedini et al., "Traveling-Wave-Based Methodology for WideArea Fault Location in Multiterminal DC Systems," IEEE Transactions on Power Delivery, vol. 29, no. 6, pp: 2552-2560, 2014.

(11) E. G. Carrano, F. G. Guirnaraes, R. H. C. Takahashi et al., "Electric distribution network expansion under load-evolution uncertainty using an immune system inspired algorithm," IEEE Transactions on Power Systems, vol. 22, no. 2, pp: 851-861, 2007.

(12) H. X. Guan, G. G. Hao, H. T. Yu, "Study of fault location algorithm for distribution network with distributed generation based on IGA-RBF neural network," International Journal of Grid and Distributed Computing, vol. 9, no. 7, pp: 33-42, 2016.

(13) C. J. Fan, K. K. Li, W. L. Chan et al., "Application of wavelet fuzzy neural network in locating single line to ground fault (SLG) in distribution lines," International Journal of Electrical Power \& Energy Systems, vol. 29, no. 6, pp: 497-503, 2007.

(14) A. Bahmanyar, S. Jamali, "Fault location in active distribution networks using non-synchronized measurements." International Journal of Electrical Power \& Energy Systems, vol. 93, pp: 451-458, 2017.

(15) N. I. Elkalashy, N. A. Sabiha, M. Lehtonen, "Earth Fault Distance Estimation Using Active Traveling Waves in Energized-Compensated MV Networks," IEEE Transactions on Power Delivery, vol. 30, no. 2, pp: 836-843, 2015.

(16) P. C. Chen, V. Malbasa, Y. M. Dong et al., "Sensitivity Analysis of Voltage Sag Based Fault Location with Distributed Generation," IEEE Transactions on Smart Grid, vol. 6, no. 4, pp: 2098-2106, 2015.

(17) R. A. F. Pereira, L. G. W. D. Sliva, M. Kezunovic et al., "Improved fault location on distribution feeders based on matching during-fault voltage sags," IEEE Transactions on Power Delivery, vol. 24, no. 2, pp: 852-862, 2009.

(18) R. H. Salim, M. Resener, A. D. Filomena et al., "Extended fault location formulation for power distribution systems," IEEE Transactions on Power Delivery, vol. 24, no. 2, pp: 508-516, 2009.

(19) R. Salim, K. Salim, A. S. Bretas, "Further improvements on impedance-based fault location for power distribution systems," IET Generation Transmission Distribution, vol. 5, no. 4, pp: 467-478, 2011.
(20) J. Mora-Florez, J. Melendez, G. Carrillo-Caicedo, "Comparison of impedance based fault location methods for power distribution systems," Electric Power Systems Research, vol. 78, no. 4, pp: 657-666, 2008.

(21) J. U. N. Nunes, A. S. Bretas. "Impedance-based fault location formulation for unbalanced primary distribution systems with distributed generation," International Conference on Power System Technology, pp: 1-6, 2010.

(22) S. Jamali, V. Talavat, "Accurate fault location method in distribution networks containing distributed generations," Iranian Journal Electrical Computer Engineering, vol. 10, no. 1, pp: 27-33, 2011.

(23) S. F. Alwash, V. K. Ramachandaramurthy, N. Mithulananthan, "Fault-Location Scheme for Power Distribution System with Distributed Generation," IEEE Transaction on Power Delivery, vol. 30, no. 3, pp: 1187-1195, 2015.

(24) S. M. Brahma, "Fault location in power distribution system with penetration of distributed generation," IEEE Transaction on Power Delivery, vol. 26, no. 3, pp: 1545-1553, 2011.

(25) U. Eminoglu, M. H. Hocaoglu, "A new power flow method for radial distribution systems including voltage dependent load models," Electric Power Systems Research, vol. 76, no. 1, pp: 106-114, 2005.

(26) A. Hoke, R. Butler, J. Hambrick et al., "Steady-state analysis of maximum photovoltaic penetration levels on typical distribution feeders." IEEE Transactions Sustainable Energy, vol. 4, no. 2, pp: 350-357, 2013.

(27) A. F. Bedoya-Cadena, R. A. Herrera-Orozco, J. J. Mora-Florez, "Fault location considering load uncertainty and distributed generation in power distribution systems," IET Generation Transmission and Distribution, vol. 9, no. 3, pp: 287-295, 2015.

(28) C. Orozco-Henao, A. S. Bretas, J. Marin Quintero et al., "Active distribution network fault location methodology: A minimum fault reactance and Fibonacci search approach." International Journal of Electrical Power \& Energy Systems, vol. 84, pp: 232-241, 2017.

(29) L. T. Tung, "Second-Order Radial-Asymptotic Derivatives and Applications in Set-Valued Vector Optimization," Pacific Journal of Optimization, vol. 13, no. 1, pp: 137-153, 2017.

(30) N. Assimakis, M. Adam, C. Triantafillou, "Lainiotis filter, golden section and Fibonacci sequence," Signal Processing, vol. 93, no. 4, pp: 721-730, 2013.

(31) U. Eminoglu, M. H. Hocaoglu, "Distribution systems forward/backward sweep-based power flow algorithms: A review and comparison study," Electric Power Components and Systems, vol. 37, no. 1, pp: 91-110, 2009. 
(32) C. Orozco-Henao, A. S. Bretas, J. Marin Quintero et al., "Adaptive Impedance-Based Fault Location Algorithm for Active Distribution Networks," Applied sciences, vol. 8, no. 9, pp: 100-117, 2018.

\section{References}

[1] H. Yang, X. Liu, Y. Guo, and P. Zhang, "Fault Location of Active Distribution Networks Based on the Golden Section Method," Mathematical Problems in Engineering, vol. 2020, Article ID 6937319, 9 pages, 2020.

[2] C. Orozco-Henao, A. S. Bretas, R. Chouhy-Leborgne et al., "Active distribution network fault location methodology: a minimum fault reactance and Fibonacci search approach," International Journal of Electrical Power \& Energy Systems, vol. 84, pp. 232-241, 2016. 